\title{
The Access Network: Cultivating equity and student leadership in STEM
}

\author{
Gina M. Quan \\ Department of Physics \& Astronomy, San José State University, San José, CA, 95192-0106 \\ Brianne Gutmann \\ Department of Physics, Texas State University, San Marcos, TX, 78666 \\ Joel C. Corbo and Benjamin Pollard \\ University of Colorado Boulder, Boulder, CO, 80309 \\ Chandra A. Turpen \\ Department of Physics, University of Maryland, College Park, MD 20742
}

\section{The Access Network}

The Access Network consists of nine university-based sites from across the United States working to increase access, equity, and inclusion in the physical science community. While each site differs in their implementations, they share a commitment to five core principles: 1) fostering supportive learning communities, 2) engaging students in authentic science, 3) developing students' professional skills, 4) empowering students to take ownership of their education, and 5) increasing diversity and equity in the physical sciences. The Access Network enhances the efforts of the sites in the network by cultivating intersite communication, especially facilitating the documenting and sharing of ideas across sites through a variety of network-level activities. In this paper, we articulate our network's goals and activities, share evidence of some positive outcomes, and reflect on areas for future improvement.

2019 PERC Proceedings edited by Cao, Wolf, and Bennett; Peer-reviewed, doi.org/10.1119/perc.2019.pr.Quan Published by the American Association of Physics Teachers under a Creative Commons Attribution 4.0 license. Further distribution must maintain attribution to the article's authors, cover page, and DOI. 


\section{INTRODUCTION}

Within the physical science disciplines, there has been considerable interest in improving equity and inclusion in undergraduate education $[1,2]$. Research has found that supportive student communities, structured mentoring experiences, and cohort-building summer bridge programs can all contribute to the inclusion and retention of minoritized students in STEM higher education [3-8]. These initiatives have often been initiated and led by university faculty and staff, as well as by professional societies. Given students' many forms of deep expertise $[9,10]$ we argue that it is also important that students co-lead these change initiatives.

The Access Network [11, 12] is an organization that was formed in 2015 with the goals of supporting student leadership and supporting equity efforts within university physical science departments. Access connects nine university-based organizations: the Sundial Project at Arizona State University (ASU) [13, 14], Chi-Sci Scholars at Chicago State University (CSU)[15, 16], IMPRESS at Rochester Institute of Technology (RIT) [17, 18], the Compass Project at the University of California Berkeley (UCB) [19-22], CU-Prime at the University of Colorado Boulder (CU) [23, 24], Polaris at The Ohio State University (OSU) [25], Guidance for Physics Students (Illinois GPS) at the University of Illinois at UrbanaChampaign (UIUC), Equity Constellation at the University of Maryland College Park (UMD) [26], and the North Star Project at the University of Oregon (UO) [27]. Each of these organizations is a "site" in the network.

In this paper, we describe the structure and outcomes of the Access Network. As leaders of Access, we first give an overview of our network's core principles, our programmatic goals, and our network-level activities. Then we zoom in on one goal: to empower students and faculty-especially those from marginalized and/or underrepresented groups-as agents in the design, implementation, and iterative improvement of efforts to support the success of underrepresented students. Using qualitative data from student leaders and quantitative data from student and non-student members of the Access Network, we discuss ways that we have made progress toward this goal. This work is embedded within a larger effort to create scholarly representations of our design process and our programmatic outcomes, so that others can enact similar work and critically reflect on our efforts.

Our paper's contributions are to: 1) describe our implementation of student-centered leadership, which is a unique and valuable aspect of our organization and 2) provide empirical evidence of our success toward this aim.

\section{THE ACCESS NETWORK}

Access sites were inspired by the Compass Project, a student-led organization for undergraduate physical science students at UC Berkeley [19-22]. At various points since its formation in 2007, Compass has supported students through a summer program, mentorship, an undergraduate-focused lecture series, and several semester-long courses. In 2012, Compass was recognized by the American Physical Society (APS) with its inaugural Award for Improving Undergraduate Physics Education [28].

\section{A. Network Formation}

Some site leaders formed The Access Network in 2015. The initial network consisted of Compass and five other sites (Sundial, Chi-Sci Scholars, IMPRESS, CU-Prime, and Equity Constellation). Our motivation was to support each of these sites in implementing successful programs through leveraging the collective expertise of those within the network. This expertise included years of experience running such programs, knowledge about issues of equity and inclusion, and knowledge of institutional change.

As part of our formation process, some leaders at each site (which included students and non-students) articulated the core values that underpin their sites, their long-term goals for a national network, and the set of network-level activities that would most benefit their site. We then engaged in a process of synthesizing these values, goals, and activities into our initial vision for the nascent network. The core values that emerged from this synthesis became our network's core principles:

P1. Foster supportive learning communities.

$\mathrm{P} 2$. Engage students in the process of doing authentic science.

P3. Help students develop professional skills.

P4. Empower students to take ownership of their education.

P5. Increase diversity and equity in the physical sciences.

We then articulated four goals, connected to our principles, that our network would work toward:

G1. Empower students and faculty-especially those from marginalized and/or underrepresented groupsas agents in the design, implementation, and iterative improvement of efforts to support the success of underrepresented students.

G2. Facilitate communication and community among people involved in such efforts.

G3. Create and maintain a repository of materials and strategies generated through these efforts.

G4. Support local communities in adapting these materials and program elements to their unique contexts and populations.

These principles and goals were written into an NSF grant that now funds the network. Since our formation, three other sites have joined (Polaris, Illinois GPS, and North Star). We are developing a plan for expansion to other institutions.

While each of the sites shares a common set of principles, the activities they carry out and their implementation depends on their local context, the disciplines they support, the backgrounds of their students, and their leadership struc- 
ture. Some sites only serve students in the physical sciences (e.g., Compass) whereas others include all STEM disciplines (e.g., IMPRESS). Each site offers different experiences for students: personal support (mentoring and scholarships), authentic scientific experiences (summer programs, academic year courses, and early research experience), and student empowerment and community support (student leadership roles, diversity workshops, and social activities). Some sites have strong involvement from faculty (e.g., IMPRESS, Chi-Sci Scholars), whereas others are purely student-run (e.g., CUPrime, Illinois GPS). Each site involves leadership from undergraduate and/or graduate students, called site leaders.

\section{B. Network Activities and Structure}

To support its goals (G1-G4), the network as a whole engages in several activities. An annual three-day conference (called the Assembly) allows site leaders to build community, engage in professional development, and share ideas. The Assembly is planned by a team of Assembly Fellows; each site selects one student to serve as its Assembly Fellow by whatever internal process it chooses. A set of Network Fellows (also one student per site) oversees regular communication between sites, intersite and conference travel, and documentation of network- and site-level activities. Network Fellows' activities have included organizing travel to national conferences, overseeing a "winter workshop" focused on mentoring programs, and the creation of "how-to" guides. Both the Assembly and Network fellowships are paid experiences that allow students to develop important professional skills as they lead these network-level activities.

We have adopted the term "Core Organizer" to refer to the leadership of the network at the national level. This is in distinction to "site leaders" which refer to the leadership of individual sites. In essence, Core Organizers are responsible for making the network's infrastructure run smoothly. Responsibilities include: mentorship of student fellows, overseeing grant funding and budgets, and seeking input from network members on the directions of network-level activities. Core Organizers were originally the set of current and former site leaders who wrote the grant that initially funded Access, though site leaders have transitioned in and out of this role over the past four years.

\section{DATA COLLECTION AND ANALYTICAL PROCESS}

The network's external and internal evaluation has served two purposes: 1) documenting the effectiveness of site- and network-level activities and 2) providing formative feedback on network-level activities. From 2015-2018, our external evaluation was led by Jenifer V. Helms of Inverness Research [29]. As part of this external evaluation, Helms collected surveys of Assembly attendees (2016-2018). Response rates were $61 \%$ in $2016,66 \%$ in 2017 , and $42 \%$ in 2018 . Helms collected phone interviews with Core Organizers, current and former student fellows, and administrators and department chairs at some Access sites. Of the seven students invited to be interviewed (all from different sites), five participated in interviews. Interviews with fellows focused on their experiences as fellows, how being a fellow impacted their sites, and ideas for improving the fellow experience. This paper draws on the Assembly survey and student interview data, which Helms anonymized for dissemination and documentation purposes. The Assembly survey collection and additional interviews are now being overseen by an internal network evaluation team. Some sites have conducted their own research and evaluation on their sites' programming, and have shared that anonymized data with us for network-level internal evaluation. We use data from one site's interview with one student in this paper. Participating students have given us permission to share their quotations in publications and presentations.

Quan, Gutmann, Corbo, Pollard, and Turpen analyzed these data to understand the extent to which our activities support the network in meeting its goals and embodying its principles. We did not adhere to a single methodology, but drew from thematic analysis, ethnographic methods, and other interpretive research. First, we read segments of interview transcripts and survey data and flagged data that involved one or more goals. Using this subset of data, we iteratively identified themes in the data, developed interpretations, and compared interpretations to develop richer understandings of phenomena [30]. Discussing interpretations during online meetings helped us identify the claims best supported by data. Throughout this process, we found that our goals were often interconnected and mutually-reinforcing.

For this paper, we present data describing the extent to which we are meeting G1: to empower students and facultyespecially those from marginalized and/or underrepresented groups-as agents in the design, implementation, and iterative improvement of efforts to support the success of underrepresented students. We further narrow the focus of analysis to students. We focus on this goal because our emphasis on student-centered leadership is a unique aspect of our equity work. This paper presents the full extent of the preliminary themes that we have identified, including evidence that G1 interacted with G2 and G4. Future analyses with additional data will refine our understanding of these themes.

Before presenting the data, we briefly discuss our positionality to help readers interpret our findings [31]. All of the authors of this paper are currently Core Organizers within the network and have been significantly involved in the formation and leadership of different sites in the network. Several of us (Gutmann, Pollard, Quan) contributed to network-level activities as graduate student leaders. Our involvement as network "insiders" helps us understand the context for students' statements. We also emphasize that all positive outcomes of the network are the result of roughly 100 current and former Core Organizers, fellows and site leaders. Thus, we write this paper to celebrate the collaborative efforts of many people, not to take credit for them. 


\section{RESULTS: PROGRESS TOWARD GOAL 1}

Now we turn to our analysis of how the network supported students in the design and implementation of equity efforts. We divide this section into two subsections- the first focuses on how the network supported students' engagement in sitespecific efforts, and the second focuses on how the network supported student engagement in network-wide efforts.

\section{A. How the network enabled engagement at the site level}

Site leaders found that network activities, especially the annual Assembly, benefitted their local site development. In post-Assembly surveys, 91\% (21/23) of responding 2016 attendees, $88 \%(22 / 25)$ of responding 2017 attendees, and $96 \%(24 / 25)$ of responding 2018 attendees reported that the Assembly gave them ideas for improving their local programming. Interview data from student fellows help us understand the ways in which the Assembly benefited sites. For example, Alex described the network's support in starting up a new site:

I don't know that we could have done it without their support. I am not sure if I would have gone out of my way to try to create [a site] if I wanted to, it is a pretty daunting challenge. Access has helped us think about things like how to scale it, and what is reasonable, and what should our goals and agenda be. Having that Network really helps us in forming that. We basically wrote our list of things to do while we are at the Assembly, and we got feedback from people and it really helped us.

Alex described the network's support in the early stages of their site's formation. They listed several forms of support they received at the Assembly-practical advice, goalsetting, and feedback on their plan of action. This quote emphasizes how a breadth of expertise on running site-level activities lives within the network and benefits student-leaders in the implementation of those activities at their own sites. This suggests that G4, supporting sites in adopting others' strategies and activities in their own contexts, can interact with G1; as students gain knowledge of others' implementations they may feel more empowered to implement them at their own site. Alex also described uncertainty in being able to create a site without the network's help, calling site formation a "daunting challenge." This suggests that the network not only gives students practical programmatic support, but affective (emotional) support as well.

Another student, Ami, described the ways that Access supported student leaders from existing sites in refining their sites' programs:

I feel like [Access] has definitely made a lot of what we wanted to do have a more deliberate focus. Originally, we wanted to create this community where people felt like they belonged and people felt that they had some agency, and I think the network pinpointed some obstacles that students may be feeling. They also helped us with some statistics on underrepresented groups, and how to reassure people, and it has been useful to make our goals in that area more refined and more explicit. At first we were thinking if we put a bunch of people in a room, obviously they will be happy, whereas now we have examples of things that people are doing to try to combat certain issues. It is also just reassuring to know that there are other people that think what we are doing is important. Every time we come back from the Assembly, we are all really excited because it can get a little bit tiring to do this and wonder if it is important, and it is so helpful to be around other people who think it is important.

Ami described how the network supported their site in having a "deliberate focus," which involved refining their purpose and goals. The network also helped them use evidence (e.g. "statistics on underrepresented groups") to support their equity work. The intentional and iterative nature of this account provides strong evidence of G1. They also described the value of learning about "examples of things people are doing," suggesting that one benefit of the network is for sites to gather materials from other sites and adapt those materials to their own contexts (consistent with G4). Finally, Ami also states that the annual Assembly is an important source of motivation and excitement for them in doing this work. Ami references the importance of being around others who share similar values, suggesting an interaction between G2 (facilitating community among people involved in these efforts) and G1 (doing the equity work). A theme in both students' accounts is that network activities can support students as site leaders through programmatic advice and encouragement.

\section{B. How the network enabled engagement within the network level}

Interviews with student fellows provide evidence that students valued equity work at the network level as well. Dani, an Assembly Fellow, highlighted how Access supported their professional development and helped them build community with other fellows:

Access Network is pretty interesting. I've met a couple of people already. We had different assignments [related to planning the Assembly] ...you can Facetime and physically see each other and work together, and that's pretty cool. There's this girl...she was really happy that there was another Latino in the group, like, in the Access Network, that she can talk to...[it's] just cool to have that connection to somebody. So far away, but ... if I met her, it'd be like, somebody I know...we 
kinda like, help each other out because she's physics, so if I need help with physics she can help me out, and I'm chemistry, so if she needs help with chemistry, I can help her out.

This quote illustrates how the network provides students opportunities to meet others through authentic leadership experiences, in this case co-planning the Assembly with other student leaders in virtual meetings. Dani's quote also emphasizes the role of community building (G2), especially with a fellow Latinx student, in making this leadership experience meaningful. Dani elaborated on their leadership role and the skills they developed through their fellowship:

I've never been part of trying to plan something that big, so it's like a responsibility...and really being organized is [a] big part of it. So I find that, if you have the ability to be a fellow, you get a lot of skills that you get out of it.

As Dani highlights, Access opened up authentic opportunities for their professional growth through co-planning the Assembly. Similarly, Ren (a Network Fellow) said, "there is a lot of professional development that I have learned, such as how to create grant submission guidelines, and how effective video meetings are conducted." A theme in these quotes from Dani and Ren is that their fellowship experiences supported professional skill development. This suggests that Access can provide meaningful professional development experiences for its student fellows as agents in design and implementation of network-level projects which support underrepresented students (G1).

In a different vein, Quinn described the affective benefits of taking on leadership roles in the network:

[Being a Fellow] allows me to take charge and take a lead in things that you want to get done and work toward getting them done. It also makes me feel more confident in stepping up and being that person that gets things done or helps plan or is the main planner.

Quinn describes how one of the major benefits of being a fellow is developing the confidence in "stepping up" and taking the lead on planning. We interpret this quote to mean that the structured leadership experiences within the network supported them in having positive leadership experiences, which encouraged greater confidence in engaging in future leadership. We see this as evidence of G1 because Quinn talks with a sense of agency and responsibility with respect to the work of the network and future imagined leadership roles.

\section{DISCUSSION AND CONCLUSION}

We now discuss several themes related to our first goalempowering students as agents in the design, implementation, and iterative improvement of efforts to support the success of underrepresented students - and connect those themes to Access's activities. Alex and Ami described how networklevel activities supported them as site-leaders through helping them gain leadership advice and encouragement. The shared expertise and emotional support is an intentional aspect of our network; we work toward a supportive community that bridges personal and professional life. Dani and Ren describe how fellowship experiences supported them in learning professional skills in the process of coordinating network level experiences. Core Organizers who mentor fellows explicitly attend to this development of professional skills that can benefit students beyond their fellowship experiences. Quinn and Ami both described the affective benefit of being in Access. We suspect that this relates to our holistic approach to mentoring students that recognizes that learning and organizing are emotionally complex. Through mentored fellowship experiences in a supportive community, we hope to cultivate students' sense of confidence in doing this work.

Our network's goals and principles are ultimately aspirational, and we are committed to continuous improvement toward them. Programatically, we are deveoping mechanisms for expanding our leadership team, expanding the network to include more institutions, and refining existing network activities. These mechanisms all involve strong students involvment; for example, the task force developing our network expansion plan includes eight students. In terms of evaluation, historical limitations of our analyses include a small sample of student perspectives, lack of involvement of students in our analytical process, and a need for more clarity around our goals. We recently added a student to our evaluation team who is already challenging our thinking in valuable ways. We expect that further involvment of students in evaluation would shed light on multiple aspects of $\mathrm{G} 1$, including the expansiveness of settings in which we support students, what students count as "success," and how demographic diversity matters for this goal. Finally, though not reflected in these data, several events in the network have surfaced tensions around whether we are living up to our principles. This has emerged in complex, emotional ways, and has ultimately been a source of growth for our organization. In future work, we plan to elaborate on all of these aspects of student-centered self-reflection, iteration, and growth in our organization.

\section{ACKNOWLEDGMENTS}

This work would not have been possible without past and present Core Organizers: Dimitri R. Dounas-Frazer, Scott Franklin, Angela Little, Corey Ptak, Daniel L. Reinholz, and Anna Zaniewski. We thank Fidel Amezcua, Mel Sabella, and Kristy Mardis for their contributions. We thank our external evaluator, Jenifer Helms, for data collection. This work is supported by NSF DUE-1506190, 1506235, 1506129, 1806566, 1806585, 1806668, 1806709, 1806516, 1356523. 
[1] S. Olson and D. G. Riordan, Executive Office of the President (2012).

[2] N. R. Council et al., Seeking solutions: Maximizing American talent by advancing women of color in academia: Summary of a conference (National Academies Press, 2013).

[3] U. Treisman, The College Mathematics Journal 23, 362 (1992).

[4] National Mentoring Community, URL https://www.aps.org/ programs/minorities $/ \mathrm{nmc} /$.

[5] K. G. Stassun, A. Burger, and S. E. Lange, Journal of Geoscience Education 58, 135 (2010).

[6] T. Hodapp and K. S. Woodle, Physics Today 70, 2 (2017).

[7] S. R. Gregerman, J. S. Lerner, W. Von Hippel, J. Jonides, and B. A. Nagda, The Review of Higher Education 22, 55 (1998).

[8] R. M. Goertzen, E. Brewe, and L. Kramer, International Journal of Science Education 35, 262 (2013).

[9] G. M. Quan, J. C. Corbo, N. D. Finkelstein, A. Pawlak, K. Falkenberg, C. Geanious, C. Ngai, C. Smith, S. Wise, M. E. Pilgrim, et al., Physical Review Physics Education Research 15, 010141 (2019).

[10] R. Rolón-Dow, American Educational Research Journal 42, 77 (2005).

[11] The Access Network, URL https://accessnetwork.org.

[12] D. L. Reinholz, A. Corrales, and A. Stone-Johnstone, International Journal of Students as Partners. (2019).

[13] A. M. Zaniewski and D. Reinholz, International Journal of STEM Education 3, 14 (2016).

[14] The Sundial Project, URL http://sundial.physics.asu.edu/.

[15] M. S. Sabella, K. L. Mardis, N. Sanders, and A. Little, The Physics Teacher 55, 350 (2017).

[16] The CSU Chi-Sci Scholars, URL https://msscsu.wixsite.com/ csu-sstem.

[17] C. Bertram, A. Leak, E. C. Sayre, M. B. Kustusch, and S. V.
Franklin, in Transforming Learning, Empowering Learners: The International Conference of the Learning Sciences (ICLS) (International Society of the Learning Sciences, 2016).

[18] N.-K. Marks and R. Dawod, DePaul Discoveries 5, 22 (2016).

[19] B. F. Albanna, J. C. Corbo, D. R. Dounas-Frazer, A. Little, and A. M. Zaniewski, in AIP Conference Proceedings (AIP, 2013), vol. 1513, pp. 7-10.

[20] D. Dounas-Frazer, J. Lynn, A. Zaniewski, and N. Roth, The Physics Teacher 51, 32 (2013).

[21] P. R. Gandhi, J. A. Livezey, A. M. Zaniewski, D. L. Reinholz, and D. R. Dounas-Frazer, American Journal of Physics 84, 696 (2016).

[22] The Compass Project, URL http://berkeleycompassproject. org/.

[23] D. R. Dounas-Frazer, S. A. Hyater-Adams, and D. L. Reinholz, The Physics Teacher 55, 342 (2017).

[24] CU-Prime Boulder, URL http://cuprime.org/.

[25] Polaris, URL https://u.osu.edu/saga/polaris/.

[26] G. M. Quan, C. Turpen, and A. Elby, Physical Review Physics Education Research 14, 020124 (2018).

[27] The North Star Project, URL https://northstar.uoregon.edu/.

[28] Award for improving undergraduate physics education awardees, URL https://www.aps.org/programs/education/ undergrad/faculty/awardees.cfm/.

[29] Inverness Research, URL https://inverness-research.org.

[30] R. A. Engle, F. R. Conant, and J. G. Greeno, in Video research in the learning sciences, edited by R. Goldman, R. Pea, B. Barron, and S. J. Derry (Routledge, New York, NY, 2007), pp. 239-254.

[31] K. V. England, The Professional Geographer 46, 80 (1994). 